ORIGINAL PROF-2086

\title{
SPINE SURGERY;
}

\section{Complication of iliac crest bone graft harvesting.}

\section{Dr. Abdul Satar, Dr. Muhammad Inam, Dr. Mohammad Arif, Dr. Mohammad Saeed, Dr. Imran Khan Wazir}

ABSTRACT... Objectives: The objective of this study is to find out the complication directly related to iliac bone graft harvest in spine surgery. Design: Observational prospective study. Setting: Department of Orthopedic and Spine surgery, Hayatabad Medical Complex Peshawar. Period: January 2007 to April 2012 on 139 patients. Material and method: Only those cases were included in whom bone grafting was done for fusion as part of their spine surgery and were successfully followed for at least 6 months. Results: Out of 139 patients 59(42.4\%) were female patients while $80(57.6 \%)$ were male. Minimum age of the patients was 4 years while maximum was 70 years. In 119(85.6\%) patients cortico-cancellous bone graft was taken. While in 20(14.4\%) patients, tri-cortical graft was taken. In majority 106(76.3\%) cases graft was obtained from the posterior iliac crest while in $33(23.7 \%)$ it was obtained from the anterior iliac crest. $45(32.4 \%)$ had some pain at the bone graft site. $8(5.8 \%)$ had early deep infection while $6(4.3 \%)$ had early superficial infection. Nine $(6.4 \%)$ of our patients had nerve injury evident by parasthesia in the zone of distribution. Conclusions: lliac crest is an excellent source and best available material for autogenous bone grafting. However it is not free of complications. The most common complications are persistent chronic donor site pain, infection and heamatoma.

Key words: Iliac crest, Bone graft, Complications. Spine Surgery

Article Citation

Satar A, Inam M, Arif M, Saeed M, Wazir, IK. Spine surgery; Complication of iliac crest bone graft harvesting. Professional Med J 2013;20(2): 266-271.

\section{INTRODUCTION}

Spinal fusion is the ultimate long term goal of most spine surgeries done for degenerative disease, deformity or fracture of the spine. Although still not clearly demonstrated, it is believed that a solid fusion will improve outcome in these patients with spinal pathologies. The rate of fusion varies from 40 to 100 percent in different studies ${ }^{1,2}$. It depends not only on the technique used but also on the patient general health status and co morbidities. The most common type of fusion is posterolateral fusion. To enhance fusion rates, interbody fusion was introduced which can be done from anterior as well as posterior. Combine posterolatral and inter-body fusion is known as 360 degree fusion and claims $100 \%$ fusion rate ${ }^{3}$.

All these different kind of fusion uses autogenous or allogenic bone or bone substitute material to bridge the gap, stimulate fusion and provide mechanical stability in some case. Allogenic cancellous bone is used in many centers to achieve spinal fusion. It can be used in large quantities, avoids second procedure and its potential morbidity ${ }^{6}$. It is not freely available in our setup, carries additional cost and has the risk of infection transmission. Considering biological properties, it is inferior to autogenous bone graft material. There is widespread use of recombinant human bone morphogenic protein (rhBMP2) in many spine centers to enhance spinal fusion. But its use is still controversial and FDA only approved its use for anterior lumber interbody fusion in cage. Not only is that it is very expensive it has got a list of specific complications ${ }^{7}$.

Apart from some revision surgeries, in most of the cases autogenic iliac bone graft is the best available material. Autogenous iliac crest bone graft is considered the gold standard. Without any additional cost large amount of bone can be harvested. This is the only area from where tricortical bone can be obtained ${ }^{4}$. But the availability is limited especially in revision surgeries and has donor side morbidity. All this led to the search of other material to overcome these short comings ${ }^{5}$.

In our area and most of the Asian countries it is most 
widely used method for achiveing fusion. However it has a very significant morbidity. Complication rates in some series are reported as high as $39 \%{ }^{8}$. The most common complication is persistent chronic donor site pain, regardless whether bone graft is taken from anterior or posterior iliac crest. Common complications are infection and heamatoma. Other documented complications are neurovascular injury, visceral injury, herniation of visceral contents and sacroiliac joint instability. Visceral perforations, pelvic fracture and gait disturbance are rare but drastic complications ${ }^{9}$.

We routinely use iliac crest bone graft to achieve spinal fusion in variety of spine surgeries for the last few years. In this study we present our rate of complication directly related to bone graft harvest.

\begin{tabular}{|c|c|c|}
\hline Sex & No. of cases & Percentage \\
\hline Male & 12 & 66.7 \\
\hline Female & 06 & 33.3 \\
\hline
\end{tabular}

Table-I. Sex distribution $(n=18)$

\section{MATERIAL AND METHODS}

This observational prospective study was performed in the department of Orthopedic and Spine surgery, Hayatabad Medical Complex Peshawar from January 2007 to April 2012 on 139 patients. Only those cases were included in whom bone grafting was done for fusion as part of their spine surgery and were successfully followed for at least 6 months.

Informed written consent for spine surgery and bone graft was taken from all the patients a day before surgery. Specifically it was mentioned to the patients that bone will be taken from iliac bone via separate incision.

On the day of surgery bone graft was taken from anterior or posterior iliac crest depending on the position of the patient. In prone position bone graft was taken from posterior iliac crest while in lateral position or supine position from anterior iliac crest. Incision was made over the iliac crest and bone reached after layer dissection. Using electro cautery the outer table of the iliac wing or both tables for tri-cortical grafts were exposed subperiosteally. Using osteotome, cortico-cancellous strips were removed from the outer table of iliac crest under vision. After this, cancellous bone was taken with curette leaving the inner table intact. For tri-cortical grafts both tables were prepared and the block was taken using oscillating saw or osteotome. Graft from posterior crest in obese people poses a significant challenge. Wound was packed until the end of spine surgery. At the end wound was examined for active bleeding which was stopped. Significant ooze from the bone was treated with bone wax to stop bleeding. Wound washed with normal saline and closed in layers over suction drain. At the end bupvicane was injected into the wound, to reduce postoperative pain.

Post operative pain was addressed individually for each patient. Intravenous antibiotics were used for 3 days and thereafter oral antibiotics were given in all patients. Drain was removed next day and dressing was changed on third day. Patients were discharged home on third day and then followed at 2 weeks, 1, 2, 3 and 6 month. Data was collected about complications like donor site pain, infection, nerve injury, hematoma formation and any other complications. All the data were collected with the help of proforma and entered and analyzed by SPSS version 10.

\section{RESULTS}

In our study we included a total of 139 patients in whom autogenous iliac crest bone graft was taken. Out of these $59(42.4 \%)$ were female patients while $80(57.6 \%)$ were male. Minimum age of the patients was 4 years while maximum was 70 years. Mean age of our patients was $32.4(S D=16.2)$. This huge variance is because different aged patients with quite different spine pathologies were included in this study. 
Most of the patients were in the age group 20 to 40 years, $41.7 \%$ of the total patients. This is largely due to patients with spine fractures. $28.8 \%$ patients are in the age group below 20 and these are largely patients with spine deformity.

In 119(85.6\%) out of 139 patients cortico-cancellous bone graft was taken. While in $20(14.4 \%)$ patients, tricortical graft was taken (table-I). ri-cortical graft was only taken during cervical spine discectomy or corpectomy. In all other patients cortico-cancellous chips was required for fusion. Site of the bone graft was mainly dependent on the ease of surgeon. In $61(43.9 \%)$ patients graft was taken from the left crest while in $78(56.1 \%)$ from the right crest. In majority $106(76.3 \%)$ cases graft was obtained from the posterior iliac crest while in 33(23.7\%) it was obtained from the anterior iliac crest (table II).

\begin{tabular}{|c|c|c|c|c|}
\hline & Frequency & Percent & $\begin{array}{c}\text { Valid } \\
\text { Percent }\end{array}$ & $\begin{array}{c}\text { Cumulative } \\
\text { Percent }\end{array}$ \\
\hline $\begin{array}{l}\text { Cortico- } \\
\text { cancelous }\end{array}$ & 119 & 85.6 & 85.6 & 85.6 \\
\hline Tricortical & 20 & 14.4 & 14.4 & 100.0 \\
\hline Total & 139 & 100.0 & 100.0 & \\
\hline
\end{tabular}

Table-I. Bone graft type

\begin{tabular}{|l|c|c|c|c|}
\hline & Frequency & Percent & $\begin{array}{c}\text { Valid } \\
\text { Percent }\end{array}$ & $\begin{array}{c}\text { Cumulative } \\
\text { Percent }\end{array}$ \\
\hline Left & 61 & 43.9 & 43.9 & 43.9 \\
\hline Right & 78 & 56.1 & 56.1 & 100.0 \\
\hline Total & 139 & 100.0 & 100.0 & \\
\multicolumn{5}{|c|}{ Table-II. Side } \\
\hline
\end{tabular}

The most common complication in our series was donor site pain. Out of 139 patients 45(32.4\%) had some pain at the bone graft site (table III). Pain severity at 6 months on VAS was measured. Minimum Score on VAS scale was 3 while maximum 7 . Mean VAS was $4.1(\mathrm{SD}=1.07)$. Out of 45 patients with pain, 32 (71.1\%) had mild (VAS 3and4) pain and not disturbing their routine. While the rest had significant pain which limits their routine and required some medication. The next common complication was infection of the bone graft site which was14 (10.1\%) in our series (table IV). Out of these $14,8(5.8 \%)$ had early deep infection while $6(4.3 \%)$ had early superficial infection. Deep infection was treated by early debridement and wound wash while superficial responded to antibiotics. Nine (6.4\%) of our patients had nerve injury evident by parasthesia in the zone of distribution. As most of over patients had posterior iliac crest graft, we had 7 patients with parasthesia in the superior gluteal region. In 2 patients there was parasthesia in the lateral thigh region.

We had no complication like hematoma formation, iliac bone fracture, bowel perforation, abdominal hernia, gait abnormality or other rare complications.

\begin{tabular}{|c|l|c|c|c|c|}
\hline \multicolumn{2}{|c|}{} & Freq. & Percent & $\begin{array}{c}\text { Valid } \\
\text { Percent }\end{array}$ & $\begin{array}{c}\text { Cum. } \\
\text { Percent }\end{array}$ \\
\hline \multirow{3}{*}{ Valid } & $\begin{array}{l}\text { Not } \\
\text { present }\end{array}$ & 94 & 67.6 & 67.6 & 67.6 \\
\cline { 2 - 6 } & Present & 45 & 32.4 & 32.4 & 100.0 \\
\cline { 2 - 6 } & Total & 139 & 100.0 & 100.0 & \\
\hline \multicolumn{5}{|c|}{ Table-III. Pain at bone graft site } \\
\end{tabular}

\begin{tabular}{|l|c|c|c|c|}
\hline & Freq. & Percent & $\begin{array}{c}\text { Valid } \\
\text { Percent }\end{array}$ & $\begin{array}{c}\text { Cum. } \\
\text { Percent }\end{array}$ \\
\hline Early deep infection & 8 & 5.8 & 5.8 & 5.8 \\
\hline None & 125 & 89.9 & 89.9 & 95.7 \\
\hline Early superficial & 6 & 4.3 & 4.3 & 100.0 \\
\hline Total & 139 & 100.0 & 100.0 & \\
\hline \multicolumn{5}{|c|}{ Table--IV. Post op. Infection } \\
\hline
\end{tabular}

\section{DISCUSSION}

Spine fusion surgeries are at constant rise during the last few decades. Only in USA around 300,000 spine fusion surgeries are performed yearly.

Transpedicular screw fixation with autogenous bone 
graft from the iliac crest may be considered as a gold standard for lumbar spine fusion ${ }^{10}$.

These procedures have quite common complications. Arrigton ED in large retrospective review of 414 patients found $10 \%$ minor and $5.8 \%$ major complications. Minor complications were like superficial infection, hematoma and seroma. All other complications were regarded as major complications ${ }^{11}$. Our complications were quite high, like $32.4 \%$ had chronic donor site pain, although majority had mild pain. We had deep infection in $4.3 \%$ of the patients and in $6.4 \%$ we had nerve injury although it does not disturbed daily routine of the patients. In their study all type of patients with different orthopedic pathologies were included, while in our study only patients with spine pathologies were included. In these procedures usually large amount of bone graft is harvested and often extensive dissection of the crest is required.

Like other studies, the most common complication in our study was chronic donor site pain. $32.4 \%$ of our patients had some pain at 6 months. Out of these 13(9.3\%) had significant pain at 6 months. Summers BN reported $25 \%$ patients with sever donor site pain at 6 months, who underwent iliac crest bone harvest during lumbar spine fusion surgery ${ }^{12}$. Delawi $D$ et al reported donor site pain in $40 \%$ of patients ${ }^{13}$. In a recent prospective study Sasso RC et al reported donor site pain in $31 \%$ cases at 2 years ${ }^{8}$.

Fourteen (10.1\%) of our patients had infection of the bone graft site. Out of these 6 patients had minor superficial infection while 8 had deep infection, which required additional surgery. Nassr $A$ et al reported superficial infection of donor site in $15(9 \%)$ of their patients. While 1 patient devolved deep infection requiring debridement and $\mathrm{i} / \mathrm{v}$ antibiotics ${ }^{14}$.

Another commonly reported complication is numbness around the incision or in the distribution of superior gluteal nerve or lateral cutaneous nerve ${ }^{15}$.
Silber et al reported abnormal sensation in $15.7 \%$ out of total 139 patients $^{16}$. Although in majority of the patients it was not disturbing. Robertson at al reported persistent sensation loss in $10 \%$ patients at 12 months in patients undergoing posterior spinal fusion ${ }^{17}$. In our study we had numbness or sensation abnormality in $9(6.4 \%)$ of our patients.

Hematoma formation is also commonly reported in the literature. AhImann et al reported large hematoma formation in $9.6 \%$ patients for anterior iliac crest graft a harvest and $7.5 \%$ for posterior iliac crest. We have no hematoma formation in our series. It may be due to the judicious use of drain and application of bone wax to the bleeding bone surface in selected $\operatorname{cases}^{18}$. We had no complication like iliac bone fractures, visceral perforation, hernias and gait abnormality.

\section{CONCLUSION}

lliac crest is an excellent source and best available material for autogenous bone grafting. Autogenous iliac crest bone graft is considered to be the gold standard because without any additional cost large amount of bone can be harvested and from where tricortical bone can be obtained. However the availability is limited especially in revision surgeries and has donor side morbidity.

Copyright@ 15 Jan, 2013.

\section{REFRENCES}

1. Lee CS, Hwang CJ, Lee D, Kim YT, Lee HS. Fusion Rates of Instrumented Lumbar Spinal Arthrodesis according to Surgical Approach: A Systematic Review of Randomized Trials. Clin Orthop Surg. Mar 2011;3(1):39-47.

2. ChouR, Baisden J, Carragee EJ, Resnick DK, Shaffer WO, Loeser JD. Surgery for low back pain: a review of the evidence for an American Pain Society Clinical Practice Guideline. Spine (Phila Pa 1976). May 2009;34(10):1094-109.

3. Hackenberg L, Halm H, Bullmann V, Vieth V, Schneider M, Liljenqvist U. Transforaminal lumbar interbody 
fusion: a safe technique with satisfactory three to five year results. Eur Spine J. Aug 2005; 14(6):551-6.

4. Belthur MV, Conway JD, Jindal G, Ranade A, Herzenberg JE. Bone graft harvest using a new intramedullary system. Clin Orthop Relat Res .Dec 2008;466(12):2973-2980.

5. Dimar JR 2nd, Glassman SD, Burkus JK, Pryor PW, Hardacker JW, Carreon LY. Two-year fusion and clinical outcomes in 224 patients treated with a single-level instrumented posterolateral fusion with iliac crest bone graft. Spine J. Nov 2009;9(11):880-5.

6. Chau MT, Mobbs RJ. Bone graft substitutes in anterior cervical discectomy and fusion. Eur Spine J. Apr 2009:18(4):449-64.

7. Epstein NE. Pros, cons, and costs of INFUSE in spinal surgery. Surg Neurol Int.2011;2:10.

8. Sasso RC, LeHuec JC, Shaffrey C. Iliac crest bone graft donor site pain after anterior lumbar interbody fusion: a prospective patient satisfaction outcome assessment. J Spinal Disorder Tech.Feb 2005;18:7781.

9. MccCabe JP, Heneghan HM. Use of autologous bone graft in anterior cervical decompression: morbidity \& quality of life analysis. BMC Musculoskeletal Disorder.2009;10:158.

10. Putzier M, Strube P, Funk JF, Gross C, Monig HJ, Perka C et al. Allogenic versus autologous cancellous bone in lumbar segmental spondylodesis: a randomized prospective study. Eur Spine J. May 2009;18(5). 68795.

11. Arrigton ED, Smith WJ, chambers HG, Bucknell AL, Davino NA. Complications of iliac crest bone graft harvesting. Clin Orthop Relat Res.Aug;329:300-9.
12. Summers BN, Eiesenstein SM. Donor site pain from the ilium. A complication of lumbar spine fusion. $J$ Bone Joint Surg Br. Aug !989;71(4):300-9.

13. Delawi D, DhertWJ, Castelein RM, Verbout AJ, Oner FC. The incidence of donor site pain after bone graft harvesting from the posterior iliac crest may be overestimated: a study on spine fracture patients. Spine(Phila Pa 1976). Aug 2207;32(17):300-9.

14. Nassr A, Khan MH, Ali MH, Espiritu MT, Hanks SE, Lee $J Y$ et al. Donor site complications of autogenous nonvascularized fibula strut graft harvest for anterior cervical corpectomy and fusion surgery: experience with 163 consective cases. Spine J. Nov 2009; 9(11):893-8.

15. Kim DH, Rhim R, Li L, Martha J, Swaim BH, Banco RJ et al. Prospective study of iliac crest bone graft harvest site pain and morbidity. Spine J. Nov 2009;9(11):8938.

16. Anderson DG, Silber JS, Daffner SD, Brislin BT, Leland JM, Hilibrand AS, Vaccaro AR, Albert TJ. Donor site morbidity after anterior iliac crest bone harvest for single-level anterior cervical discectomy and fusion. Spine. 2003;28:134-9.

17. Robertson P, Wray AC. Natural history of posterior iliac crest bone graft donation for spinal surgery: a prospective analysis of morbidity. Spine. 2001; 26:1473-6.

18. Ahlmann E, Patzakis M, Roidis N, Shepherd L, Holtom P. Comparison of anterior and posterior iliac crest bone grafts in terms of harvest-site morbidity and functional outcomes. J bone Joint Surg Am. May 2002;84(5):716-20. 


\section{AUTHOR(S):}

1. DR. ABDUL SATAR

FCPS (Ortho)

Medical Officer

Department of Orthopedic and Spine Surgery

PGMI Hayatabad Medical Complex Peshawar

2. DR. MUHAMMAD INAM

MBBS, MRCS(UK), FCPS (Ortho)

Senior Registrar

Department of Orthopedic and Spine Surgery

PGMI Hayatabad Medical Complex Peshawar

3. DR. MOHAMMAD ARIF

MBBS, FCPS (Ortho)

Professor and Head

Department of Orthopedic and Spine Surgery

PGMI Hayatabad Medical Complex Peshawar

\section{Dr. Mohammad Saeed, M.D}

5. Dr. Imran Khan Wazir, FCPS

Correspondence Address:

Dr Muhammad Inam

Department of Orthopedic and Spine Surgery PGMI Hayatabad Medical Complex Peshawar dr_mohammadinam@yahoo.co.uk
Article received on: 20/09/2012 Accepted for Publication: 15/01/2012 Received after proof reading: 02/02/2013

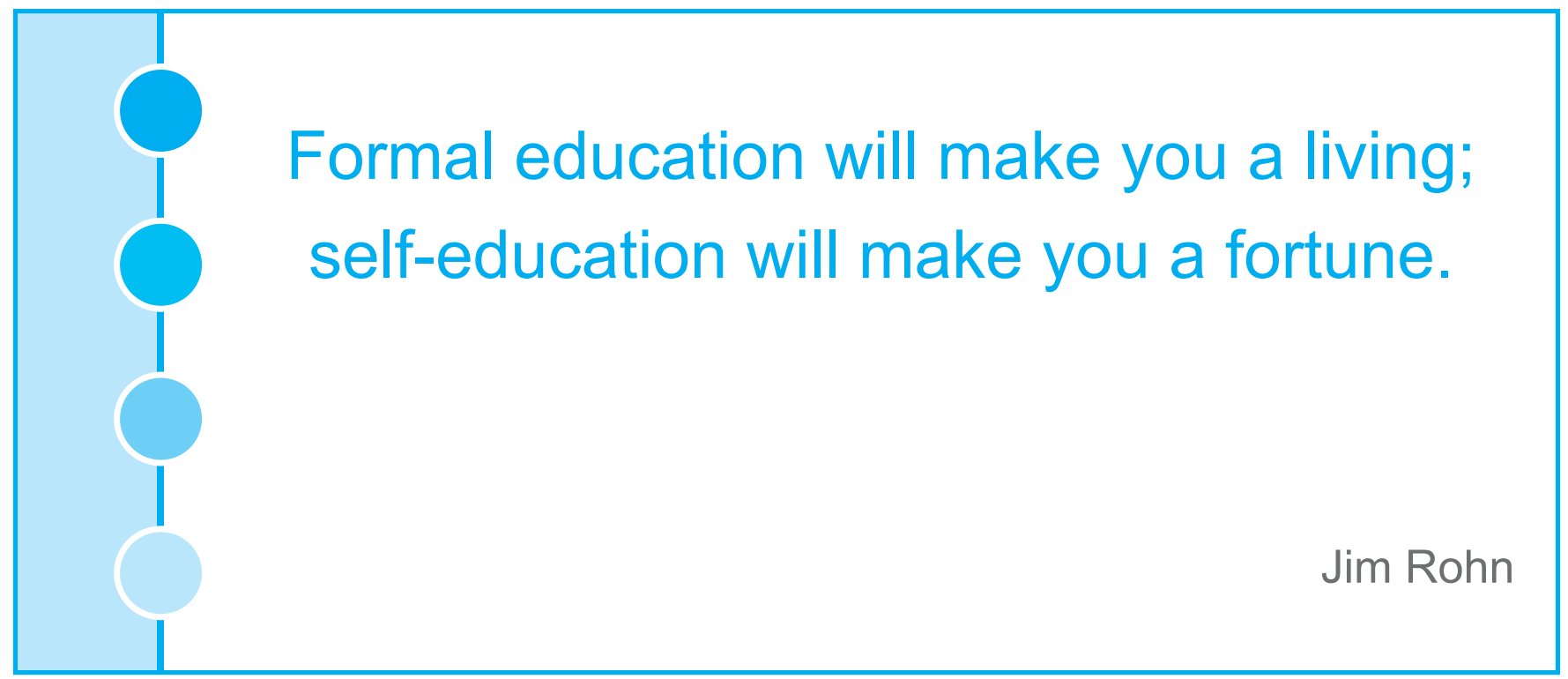

